Infusionsther Transfusionsmed 1993;20(suppl 1):2

\title{
Impressum, Vol. 20, Supplement 1, 1993
}

Offizielles Organ

der Deutschen Gesellschaft für Transfusionsmedizin

und Immunhämatologie

Gründungsherausgeber

H. Reissigl, Innsbruck

Herausgeber

J. Eckart, Augsburg V. Kretschmer, Marburg K. Meßmer, München K. Peter, München W.

Stangel, Hannover K.-H. Usadel, Frankfurt

Schriftleiter

H. Forst, München

Assistent des Schriftleiters

B. Zwißler, München

Wissenschaftlicher Beirat

M. Adolph, Augsburg F. W. Ahnefeld, Ulm J. Askanazi, New York C. Baldamus, Köln H.

Bardenheuer, München J.-F. Baron, Paris K.-H. Bäßler, Mainz W. Behrendt, Aachen H.

Borberg, Köln U. B. Bruckner, Ulm W. Dick, Mainz J. Eckart, Augsburg R. Eckstein, Erlangen

A. Encke, Frankfurt K. Falke, Berlin U. Finsterer, München H. Forst, München L. Frey, München Y. Fujita, Okayama L. Gattinoni, Monza M. Georgieff, Ulm

A. Grünert, Ulm

H. J. Gurland, München

P. Hanfland, Bonn

M. Heberer, Basel

J. P. Isbister, Sydney

K. Jauch, München

W.-P. Kloevekorn, Bad Nauheim

E. Kolb, München

W. Kox, Essen

G. C. Kramer, Galveston

H. G. Kress, Würzburg

V. Kretschmer, Marburg

B. Kubanek, Ulm

P. Kühnl, Hamburg

H. Laubenthal, Bochum W. Mempel, München K. Meßmer, München N. Mutz, Innsbruck U. E.

Nydegger, Bern W. Oettinger, Trier K. Peter, München

P. Prien, Münster

H. Reissigl, Innsbruck

D. Roelcke, Heidelberg

R. Roos, München

W. Schleinzer, Hamburg 
D. Schönitzer, Innsbruck

H.-P Schuster, Hildesheim

H.-G. Sieberth, Aachen

R. A. K. Stahl, Frankfurt

W. Stangel, Hannover

U. Suchner, München

L. Sunder-Plassmann, Ulm

K.-H. Usadel, Frankfurt

E. Wenzel, Homburg I Saar

K. Werdan, München

K. Widhalm, Wien G. Wolfram, München R. Zander, Mainz B. Zwißler, München

Supplement 1 zu Band 20, April 1993: ISBN 3-8055-5813-9

Ladenpreis dieses Sonderheftes DM 60,- incl. MwSt.

Abonnenten erhalten es unberechnet.

Die Zeitschrift erscheint zweimonatlich: pro Jahr erscheint 1 Band zu je 6 Heften.

DGTI-Mitglieder erhalten die Zeitschrift im Rahmen ihrer Mitgliedschaft.

Bezugspreis für Jahrgang 20, 1993: DM 159,-/ öS 1113,-, SFr 124,-. 1 Einzelheft kostet DM 30-1 öS 210,-1 SFr 23,-, einschließlich MwSt., zuzüglich Postgebühren. Der Abonnementpreis ist im voraus zahlbar. Das Abonnement der Zeitschrift läuft weiter, wenn es nicht spätestens 4 Wochen vor Abschluß eines Bandes abbestellt wird. Abonnementbestellungen können bei jeder Buchhandlung oder direkt beim Verlag aufgegeben werden:

Bundesrepublik Deutschland/Osterreich: S. Karger GmbH, Lörracher Str. 16a, W-7800 Freiburg (ab 1.7.93: D-79115 Freiburg), Tel. (07 61) 4520 70, Fax (07 61)

45207 14, Postgiro München 614 40-808.

Schweíz: S. Karger AG, Allschwilerstr. 10, Postfach, CH-4009 Basel, Telefon (0 61) 3 061111, Telex 62652 CH, Telefax (0 61) 3061234.

Anzeigen:

S. Karger Verlag für Medizin und Naturwissenschaften GmbH, Lörracher Str. 16a, W-7800 Freiburg (ab 1. 7. 93: D-79115 Freiburg), Tel. (07 61) 452070.

Gültig ist die Preisliste Nr. 10 vom 1. Januar 1993.

Für den Inhalt außerhalb des redaktionellen Teiles (insbesondere Anzeigen, Industrieinformationen, Pressezitate und Kongreßinformationen) übernehmen Schriftleitung, Beirat und Verlag keine Gewähr.

Eine Markenbezeichnung kann warenzeichenrechtlich geschützt sein, auch wenn bei ihrer Verwendung in dieser Zeitschrift das Zeichen ${ }^{\circledR}$ oder ein anderer Hinweis auf et-wa bestehende Schutzrechte fehlen sollte. Für Satzfehler, insbesondere bei Dosie-rungsangaben, wird keine Gewähr übernommen.

Die Zeitschrift sowie alle in ihr enthaltenen einzelnen Beiträge und Abbildungen sind urheberrechtlich geschützt. Jede Verwertung, die nicht ausdrücklich vom Urheber-rechtsgesetz zugelassen ist, bedarf der vorherigen Zustimmung des Verlags. Das gilt insbesondere für Vervielfältigungen, Bearbeitungen, Übersetzungen, Mikrover-filmungen und die Einspeicherung und Verarbeitung in elektronischen Systemen. Fotokopien dürfen nur für den persönlichen Gebrauch als Eî́nzelkopien hergestellt werden. Jede im Bereich eines gewerblichen 
Unternehmens zulässig hergestellte oder benutzte Kopie dient gewerblichen Zwecken gem. § 54(2) UrhG und verpflichtet zur Gebührenzahlung an die Verwertungsgesellschaft WORT, Abt. VG Wissenschaft, Goethestraße 49, W-8000 München 2.

(C) Copyright 1993 by S. Karger

Verlag für Medizin und Naturwissenschaften $\mathrm{GmbH}$

Lörracher Str. 16a, D-W-7800 Freiburg (ab 1.7. 93: D-79115 Freiburg)

Verlagsleitung: Steven Karger

Presserechtlich verantwortlich: Georg Brunner

Redaktionsassistenz: Martina Zeller

Anzeigenverwaltung: Christiane Opitz

Satz und Druck: Konkordia Druck GmbH, Eisenbahnstraße 31

W-7580 Bühl (ab 1.7. 93: D-77815 Bühl) 